\title{
7-Difluoromethoxyl-5,4'-di-n-octyl genistein inhibits the stem-like characteristics of gastric cancer stem-like cells and reverses the phenotype of epithelial-mesenchymal transition in gastric cancer cells
}

\author{
XIAOZHENG CAO ${ }^{1,2^{*}}, \mathrm{KAIQUN}^{\mathrm{REN}}{ }^{1 *}, \mathrm{ZHENGWEI} \mathrm{SONG}^{1}, \mathrm{DUO} \mathrm{LI}^{1}$, MEIFANG QUAN $^{1}$, \\ YU ZHENG ${ }^{1}$, JIANGUO CAO ${ }^{1}$, WENBIN ZENG ${ }^{2}$ and HUI ZOU ${ }^{1}$ \\ ${ }^{1}$ Medical College, Hunan Normal University, Changsha, Hunan 410013; ${ }^{2}$ School of Pharmaceutical Sciences \\ and Molecular Imaging Research Center, Central South University, Changsha, Hunan 410013, P.R. China
}

Received January 21, 2016; Accepted March 2, 2016

DOI: $10.3892 /$ or.2016.4848

\begin{abstract}
Difluoromethoxyl-5,4'-di-n-octyl genistein (DFOG), a novel synthetic genistein analogue, exerts anticarcinogenic activity in several types of cancers, including gastric cancer. Accumulating evidence in recent years strongly indicates the existence of cancer stem cells in gastric cancer. The objective of the present study was to investigate whether DFOG inhibits the stemness and reverses the epithelialmesenchymal transition (EMT) phenotype of gastric cancer stem-like cells (GCSLCs) derived from human gastric cancer SGC-7901 cells and to identify its potential mechanism. Sphere-forming cells (SFCs) from the SGC-7901 cells possessed the properties of GCSLCs. DFOG preferentially inhibited self-renewal, cell migration and cell invasion, and downregulated the expression of stem cell biomarkers in a dose-dependent manner. At the molecular level, these effects were accompanied by the downregulation of forkhead box M1 (FoxM1). Meanwhile, FoxM1 siRNA transfection was able to synergize the inhibition of expression of FoxM1 and Twist1 induced by DFOG in GCSLCs. In addition, we found that DFOG treatment decreased the expression of $\mathrm{N}$-cadherin and increased the expression of E-cadherin. More importantly, FoxM1 siRNA transfection cooperated with DFOG to suppress the self-renewal capacity, cell migration and cell invasion, and downregulated the expression of CD133, CD44, ALDH1, and also regulated the expression of $\mathrm{N}$-cadherin and E-cadherin.
\end{abstract}

Correspondence to: Dr Hui Zou, Medical College, Hunan Normal University, 371 Tongzipo Road, Changsha, Hunan 410013, P.R. China E-mail: zouhui308@163.com

*Contributed equally

Key words: 7-difluoromhoxyl-5,4'-di-n-octyl genistein, gastric cancer, cancer stem-like cells, gastric cancer stem-like cells, epithelial-mesenchymal transition, FoxM1, Twist
These findings showed that DFOG inhibited the stem-like characteristics of GCSLCs and reversed the EMT phenotype by modulation of FoxM1 and further decreased Twist1 expression. Our results provide a further rationale and experimental basis for using DFOG to improve the efficacy of treatment for patients with gastric cancer.

\section{Introduction}

Gastric cancer (GC) is a life-threatening malignant tumor in humans and the second most common cause of cancer-related deaths worldwide (1). Despite the extensive efforts to develop new therapeutic strategies for $\mathrm{GC}$ and despite that the incidence rates of GC have noticeably decreased in most countries in the world, it remains the most common cause of cancer-related mortality worldwide, particularly in Eastern Asian countries (2). In China, the incidence of GC ranks second among all types of malignant tumors. GC patients often present with an advanced stage at diagnosis and may also have metastasis when initial symptoms occur. As such tumor recurrence and metastasis impose great difficulty for the prevention and treatment of GC.

Cancer stem cells (CSCs), firstly found in patients with acute myeloid leukemia (3), are a unique subpopulation of cancer cells that have similar characteristics to normal stem cells and display unlimited proliferation potential, self-renewal ability and capability to generate heterogeneous lineages of cancer cells. Numerous studies have demonstrated that CSCs also exist in solid tumors such as breast and brain cancer, glioma and pancreatic cancer (4-8). CSCs were suggested to play a key role in tumor initiation, invasion, metastasis and drug resistance. Currently, CSCs have been proposed as a therapeutic target in the treatment of cancers (9).

There is growing evidence suggesting the existence of gastric cancer stem cells (GCSCs). GCSCs were firstly isolated and identified from human GC cell lines using a defined cell surface marker CD44 in 2009 (10). This study confirmed that $\mathrm{CD} 44^{+} \mathrm{GC}$ cells exhibit cancer stem cell properties such as self-renewal and high tumorigenicity. GCSCs were success- 
fully isolated using CD90 in a previous study (11). In addition, the stem cell markers CD44, CD133 and ALDH1 have been recommended for identifying GCSCs $(12,13)$. Self-renewal and lineage capacity are characteristics of all stem cells. Recently, in order to acquire CSCs, a variety of research methods have been developed based on these features. Liu et al (14) obtained GCSCs from human GC cells by cultivating cancer cells in stem-condition culture systems. This method has been used as a representative method by which to obtain GCSCs.

Forkhead box protein M1 (FoxM1), a transcription factor, is an important member of the forkhead transcription family. The International Society for Molecular and Cell Biology and Biotechnology Protocols and Research (ISMCBBPR) recognized Forkhead box protein M1 (FOXM1) as the 2010 Molecule of the Year due to its growing potential as a target for cancer therapies. The FoxM1 transcriptional factor is essential for cell cycle progression and cell survival. Upregulation of FoxM1 has been found in various types of cancers, suggesting that it may be involved in the initiation of human carcinogenesis (15-17). Accumulating evidence suggests that FoxM1 plays an essential role in cancer development and progression by enhancing drug resistance and cancer cell metastasis (18). In addition, alterations in the FoxM1 signaling pathway are reportedly associated with tumorigenesis $(19,20)$. It has been reported that overexpression of FoxM1 leads to epithelialmesenchymal transition (EMT) by the acquisition of EMT phenotype and downregulation of FoxM1 leads to the inhibition of EMT in GC cell lines (21). Moreover, FoxM1 has been shown to be a key transcription factor in regulating CSC characteristics in several studies $(22,23)$. Thus, FoxM1 may be a new molecular target for discovering tumor therapeutic agents that target CSCs.

The transcription factor Twist is considered as one of the major inducers of the EMT process, and plays a significant role in tumor metastasis through various signal transcription pathways, including Akt, Ras, signal transducer and activator of transcription 3 (STAT3), mitogen-activated protein kinase (MAPK) and Wnt signaling $(24,25)$. Twist is encoded by the Twist1 gene located on human chromosome $7 \mathrm{p} 21$ and belongs to the family of basic helix-loop-helix (bHLH) transcription factors (26). Several studies have shown that Twist1 plays an essential role in the regulation of CSC functions and features. For example, overexpression of Twist can facilitate the generation of a breast cancer stem cell phenotype (27). Activation of AKT and $\beta$-catenin pathways induced by overexpression of Twist is crucial for the maintenance of the characteristics of breast and cervical CSCs (28).

Genistein, a natural isoflavone, was first isolated from soy products. It has been demonstrated that genistein is a potential chemopreventive agent that inhibits carcinogenesis by mediating multiple regulatory pathways. Our previous studies confirmed that a novel synthetic genistein derivative, 7-difluoromethoxyl-5,4'-di-n-octyl genistein (DFOG), inhibited the growth of GC cells by suppressing FoxM1 (29) and halted the self-renewal of ovarian cancer stem cell by activating Foxo3a (30). In the present study, we investigated the effect of DFOG on gastric cancer stem-like cells (GCSLCs) and its potential mechanism for the first time. The results confirmed that DFOG can attenuate the characteristics of GCSLCs involving the decreased expression level of FoxM1.

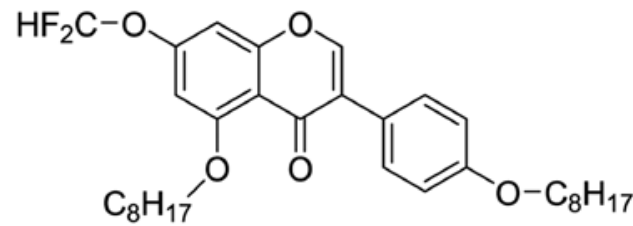

Figure 1. Chemical structure of 7-difluoromethoxyl-5,4'-di-n-octyl genistein (DFOG).

We also evaluated the effects of DFOG on EMT of GCSLCs. The results demonstrated that DFOG was able to reverse the EMT phenotype in GCSLCs by suppressing the expression of Twist1. The present study suggests that DFOG may be a potential therapeutic drug for the treatment of GC by targeting CSCs.

\section{Materials and methods}

Cell culture and reagents. Human GC SGC-7901 cells were purchased from the China Center for Type Culture Collection (CCTCC; Wuhan, China) and were maintained in Dulbecco's modified Eagle's medium (DMEM) supplemented with $10 \%$ fetal bovine serum (FBS), $100 \mathrm{IU} / \mathrm{ml}$ penicillin and $100 \mu \mathrm{g} / \mathrm{ml}$ streptomycin in a humidified incubator containing $5 \% \mathrm{CO}_{2}$ at $37^{\circ} \mathrm{C}$. FBS, trypsin and DMEM were purchased from HyClone (Thermo Scientific, Waltham, MA, USA).

Sphere-forming and self-renewal assay. Parental cells (PCs) were collected and washed to remove serum, and were then suspended in serum-free stem cell conditional medium containing DMEM/F12 (Gibco-Invitrogen, Carlsbad, CA, USA) supplemented with 50X B27 (Invitrogen, Carlsbad, CA, USA), $20 \mathrm{ng} / \mathrm{ml}$ EGF, $20 \mathrm{ng} / \mathrm{ml} \mathrm{bFGF}$ (both from eBioscience, Inc., San Diego, CA, USA), $4 \mu \mathrm{g} / \mathrm{ml}$ insulin, $100 \mathrm{IU} / \mathrm{ml}$ penicillin $\mathrm{G}$ and $100 \mu \mathrm{g} / \mathrm{ml}$ streptomycin. After that, the cells were plated in ultra-low adherence culture plates (6-wells) at a density of 10,000 cells $/ \mathrm{ml}$ and maintained in a humidified incubator containing $5 \% \mathrm{CO}_{2}$ at $37^{\circ} \mathrm{C}$. After 5 days of culture, the first generation of sphere-forming cells (SFCs) was obtained after trypsin-EDTA digestion. The first-generation SFCs were further cultured and expanded at a density of 10,000 cells/well in ultra-low adhesion 6-well culture plates to obtain the SFCs.

Scratch assays. The PCs and third-generation SFCs were seeded in 6-well plates at a density of $4 \times 10^{5} /$ well in DMEM supplemented with $10 \%$ FBS. When the cells grew to $85 \%$ confluency, the wound was generated by scratching the surface of the plates in the central region with a $200 \mu \mathrm{l}$ pipette tip. Washing was performed 2 times using phosphate-buffered saline (PBS) to remove floating cells and debris. The cells were incubated for $48 \mathrm{~h}$, and were imaged at 0 and $48 \mathrm{~h}$ in the same location of the wound, respectively. The numbers of cells in the scratch area were counted, and the migratory rate of the cells was determined in relation to the migratory rate of the PCs considered as the standard migration rate (100\%).

Transwell chamber invasion assay in vitro. DMEM (1.0 ml) supplemented with $10 \%$ FBS as a chemical inducer was added 
A

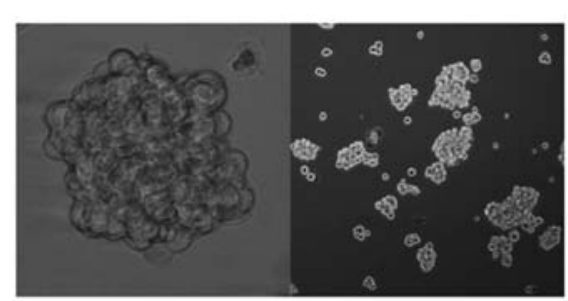

C

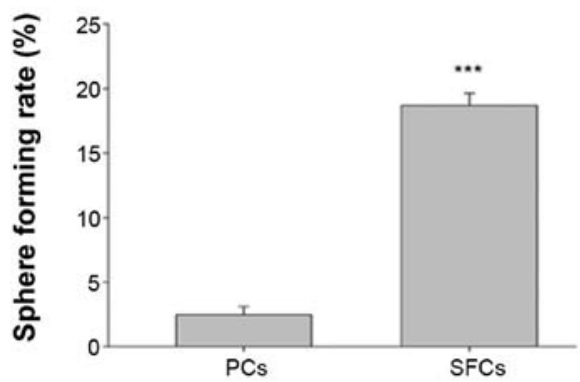

B

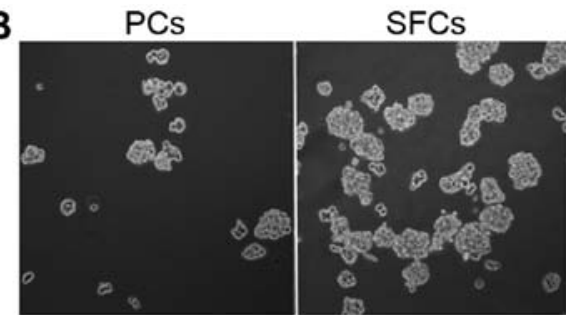

D

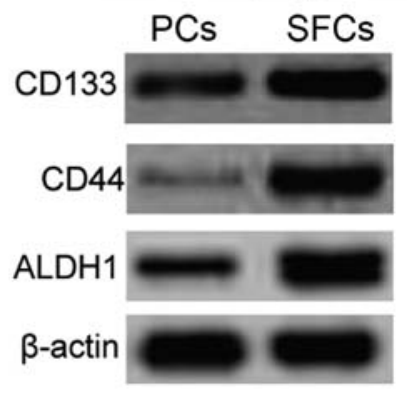

Figure 2. Identification of GCSLCs in the SGC-7901 cell line. (A) Tumor sphere from SGC-7901 cells in the stem cell culture system. (B) The sphere forming ability of parental cells (PCs) and the third-generation sphere-forming cells (SFCs). (C) Statistical analysis of B; each experiment was performed in triplicate. ${ }^{* * * *} \mathrm{P}<0.001$ vs. the PCs. (D) Western blot analysis showed that protein expression levels of CD133, CD44 and ALDH1 were higher in the SFCs.

to the 24-well cell culture plate which was then embedded in the Transwell chamber. A total of 10,000 PCs or SFCs were plated in the top chamber of the Transwell coated with Matrigel. After being cultured for $24 \mathrm{~h}$, the cells that had not invaded through the pores of the insert were cleared with a sterile cotton swab and discarded. The cells that invaded to the lower chamber were fixed with methanol, stained with crystal violet and counted under an optical microscope with the migration rate of the PCs or SFCs treated with $0.1 \%$ dimethyl sulfoxide (DMSO) considered as the standard invasion rate $(100 \%)$.

Western blot analysis. The cells were washed with PBS once, and lysed in $1 \mathrm{ml}$ lysis enzyme buffer [50 mM Tris- $\mathrm{HCl}$ ( $\mathrm{pH} 7.4$ ), $150 \mathrm{mM} \mathrm{NaCl}, 0.2 \mathrm{mM}$ EDTA, $0.2 \%$ NP-40, 10\% glycerol, $1 \mathrm{M} \beta-\mathrm{Me}, 1 \mu \mathrm{g} / \mathrm{ml}$ Trasylol, $0.5 \mu \mathrm{g} / \mathrm{ml}$ leupeptin, $0.1 \mathrm{mM}$ $\mathrm{Na}_{3} \mathrm{VO}_{4}, 0.5 \mathrm{mM} 4-\mathrm{NPP}, 0.5 \mathrm{mM} \mathrm{NaF}$ and protease inhibitors]. The cells were scraped and collected after incubation for $20 \mathrm{~min}$ at $4^{\circ} \mathrm{C}$. The lysates was centrifuged at 13,200 rpm for $5 \mathrm{~min}$ at $4^{\circ} \mathrm{C}$ to prepare whole cell extracts. The Bradford assay (Bio-Rad Laboratories, Hercules, CA, USA) was used to determine the protein content. The proteins were separated and extracted using 10\% SDS-polyacrylamide gel electrophoresis, and transferred to a polyvinylidene difluoride (PVDF) membrane (Millipore, Billerica, MA, USA). The membranes were detected using mouse antibodies against CD133 (Santa Cruz Biotechnology, Santa Cruz, CA, USA), CD44, ALDH1 (both from Cell Signaling Technology, Danvers, MA, USA), N-cadherin (Upstate Biotechnology, Inc., Lake Placid, NY, USA), E-cadherin (BD Transduction), FoxM1 (Santa Cruz Biotechnology), Twist1 (Cell Signaling Technology) and $\beta$-actin (Sigma, St. Louis, MO, USA), respectively.

Statistical analysis. Data are presented as the mean $\pm \mathrm{SE}$ (mean \pm SD) and were analyzed by SPSS 17.0 statistical software. Multiple comparisons were performed by one-way ANOVA and pair-wise comparison was conducted by the LSD t-test method. The Dunnett's method was used for unequal variances. $\mathrm{P}<0.05$ as considered to indicate a statistically significant result.

\section{Results}

Synthesis and identification of DFOG. Compound 1 was synthesized and obtained using methods from the patent application (31) and was identified by a combination of NMR and mass spectral data and by comparison of these to the published literature.

Compound 1, yellow powder; EI-MS, m/z 544.1; ${ }^{1} \mathrm{H}$ NMR (500 MHz, $\left.\mathrm{CDCl}_{3}\right)$ : 0.88-0.92 (6H, m), 1.26-1.55 (24H, m), 1.77-1.83 (2H, m), 1.90-1.96 (2H, m), $3.98(2 \mathrm{H}, \mathrm{J}=6.5 \mathrm{~Hz}), 4.06$ $(2 \mathrm{H}, \mathrm{J}=6.5 \mathrm{~Hz}), 6.53(1 \mathrm{H}, \mathrm{d}, \mathrm{J}=2.0 \mathrm{~Hz}), 6.65(1 \mathrm{H}, \mathrm{t}, \mathrm{J}=72.5 \mathrm{~Hz})$, $6.69(1 \mathrm{H}, \mathrm{d}, \mathrm{J}=2.0 \mathrm{~Hz}), 6.94(2 \mathrm{H}, \mathrm{d}, \mathrm{J}=8.5 \mathrm{~Hz}), 7.44(2 \mathrm{H}, \mathrm{d}$, $\mathrm{J}=8.5 \mathrm{~Hz}), 7.77(1 \mathrm{H}, \mathrm{s}) ;{ }^{13} \mathrm{C} \mathrm{NMR}\left(125 \mathrm{MHz} \mathrm{CDCl}_{3}\right): 14.1,22.6$, 22.7, 25.8, 26.0, 28.8, 29.1, 29.2, 29.3, 29.4, 29.5, 31.8, 68.0, 69.9, 98.3, 99.1, 112.6, 113.2, 114.4, 115.2, 117.3, 123.6, 126.5, 130.3, 150.3, 154.8, 159.0, 159.1, 161.4 and 175.2. The ${ }^{1} \mathrm{H}-\mathrm{NMR}$ data were consistent with the literature (31) and ${ }^{13} \mathrm{C}-\mathrm{NMR}$ data were reported for the first time. Thus, compound 1 was identified as 7-difluoromethoxyl-5,4'-di-n-octyl genistein and named DFOG (Fig. 1).

Characteristics of GCSLCs derived from the SGC-7901 cell line. In order to enrich GCSLCs from human GC SGC-7901 cells, a stem cell conditioned medium suspension culture method was used. Under these conditions, the cells grew as non-adherent, three-dimensional sphere clusters. Fig. 2A shows the anchorage-independent spheres that formed in the SGC-7901 cells. After 5 days of incubation, the SFCs from the SGC-7901 cell line were found to generate more and larger spheroid colonies compared with that noted in the PCs (Fig. 2B and $\mathrm{C}$ ).

Next, western blotting was performed to identify protein expression of the gastric CSC markers [cluster of differentiation CD133, CD44 and aldehyde dehydrogenase 1 (ALDH1)]. The 
A

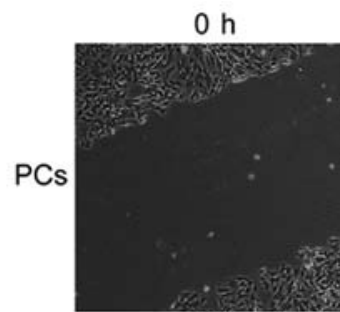

$0 \mathrm{~h}$
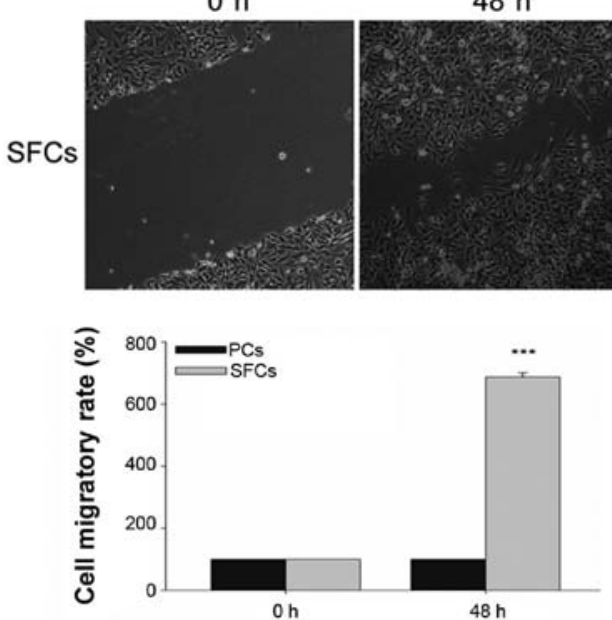

$48 \mathrm{~h}$
B
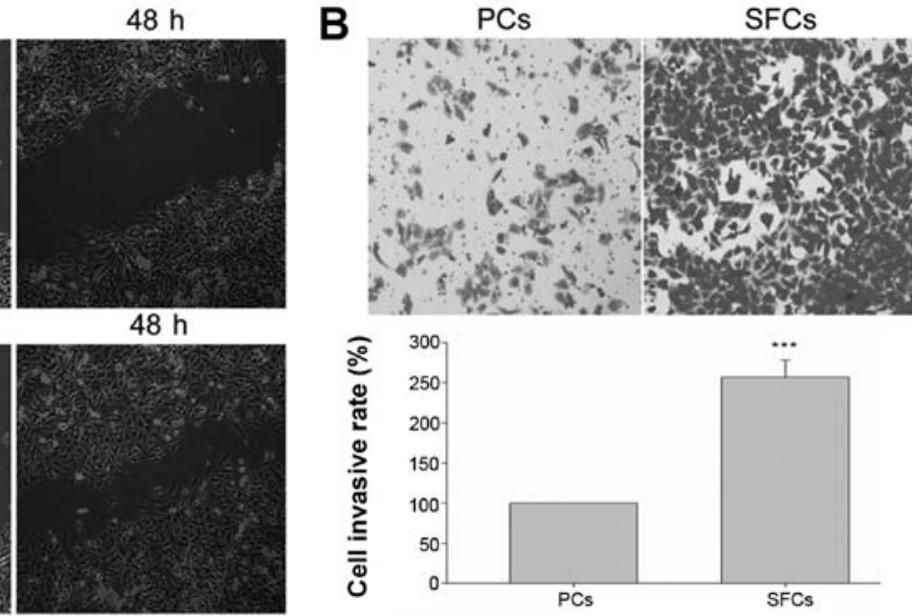

C

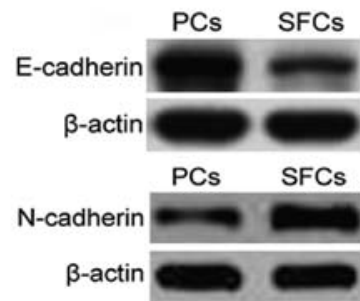

Figure 3. Mesenchymal cell characteristics of the gastric cancer stem-like cells (GCSLCs) derived from the SGC-7901 cells. (A) The cell migration rate of sphere-forming cells (SFCs) from SGC-7901 cells compared with parental cells (PCs) and the statistical analysis. ${ }^{* * *} \mathrm{P}<0.001$ vs. the PCs. (B) The invasive ability of the SFCs from SGC-7901 cells compared with PCs and the statistical analysis. ${ }^{* * *} \mathrm{P}<0.001$ vs. the PCs. (C) The protein expression levels of N-cadherin and E-cadherin in the SFCs compared with levels in the PCs.
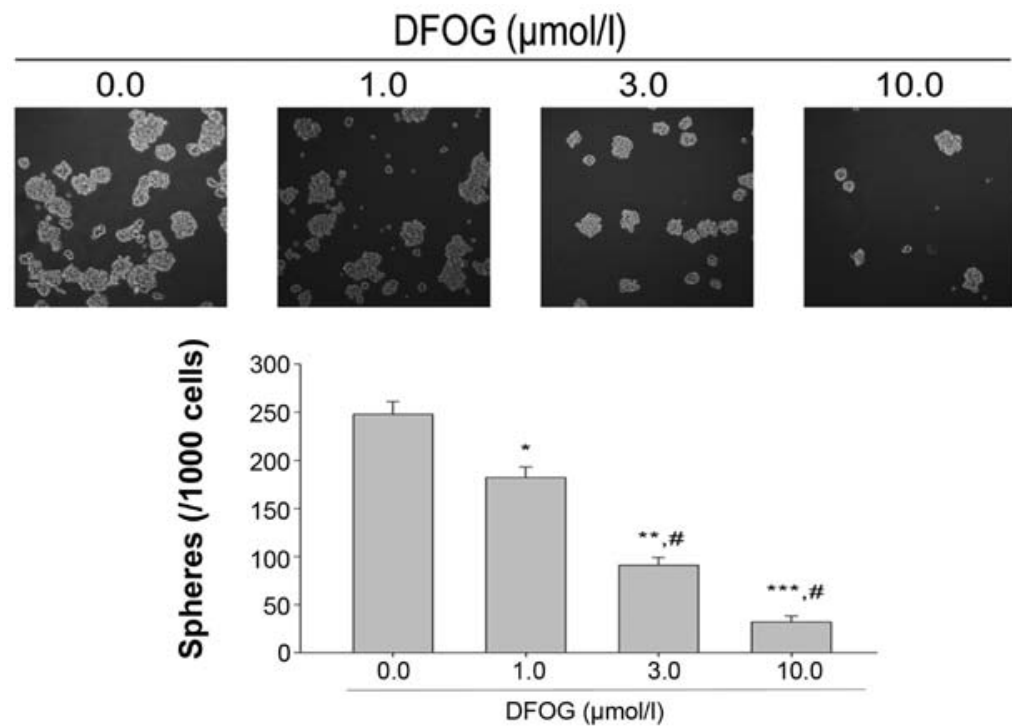

Figure 4. Inhibition of sphere-forming ability by DFOG in gastric cancer stem-like cells (GCSLCs) from SGC-7901 cells and the statistical analysis. *P<0.05 vs. the group treated with $0.1 \%$ DMSO; ${ }^{* *} \mathrm{P}<0.01$ vs. the group treated with $0.1 \% \mathrm{DMSO} ;{ }^{* * * *} \mathrm{P}<0.001$ vs. the group treated with $0.1 \% \mathrm{DMSO} ;{ }^{*} \mathrm{P}<0.05$ vs. the group treated with $1.0 \mu \mathrm{mol} / 1 \mathrm{DFOG}$.

results showed enrichment of $\mathrm{CD}_{133^{+}}, \mathrm{CD} 44^{+}$and ALDH1high populations in the SFCs derived from the SGC-7901 cells compared with the PCs (Fig. 2D). These results indicated that SFCs from the SGC-7901 cells cultured in stem cell-conditioned medium possessed GCSLC properties.

GCSLCs from the SGC-7901 cell line show mesenchymal cell characteristics. CSCs have higher migratory and inva- sion capacities, which facilitate metastasis and growth. The migration and invasion capabilities of GCSLCs and PCs were evaluated by scratch method and Transwell chamber invasion assay in vitro, respectively. The results demonstrated that GCSLCs showed increased migratory and invasive capabilities than these capacities noted in the PCs (Fig. 3A and B). CSCs are also thought to facilitate metastasis through EMT characteristics related to the mobility of cells. We evaluated 
A

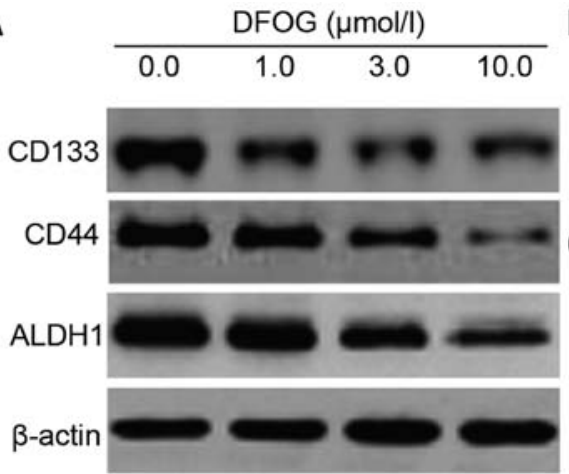

B

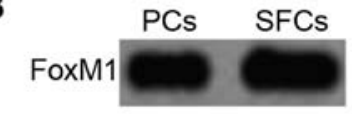

$\beta$-actin

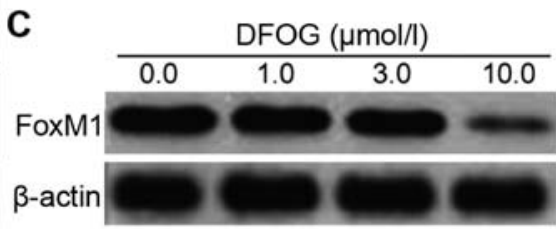

Figure 5. DFOG downregulates the expression of FoxM1 and cancer stem cell (CSC) biomarkers in gastric cancer stem-like cells (GCSLCs) from SGC-7901 cells. (A) DFOG inhibited the expression of markers CD44, CD133 and ALDH1 protein in sphere-forming cells (SFCs). (B) A higher expression level of FoxM1 was noted in the SFCs compared with the parental cells (PCs). (C) DFOG inhibited the expression of FoxM1 in the SFCs.

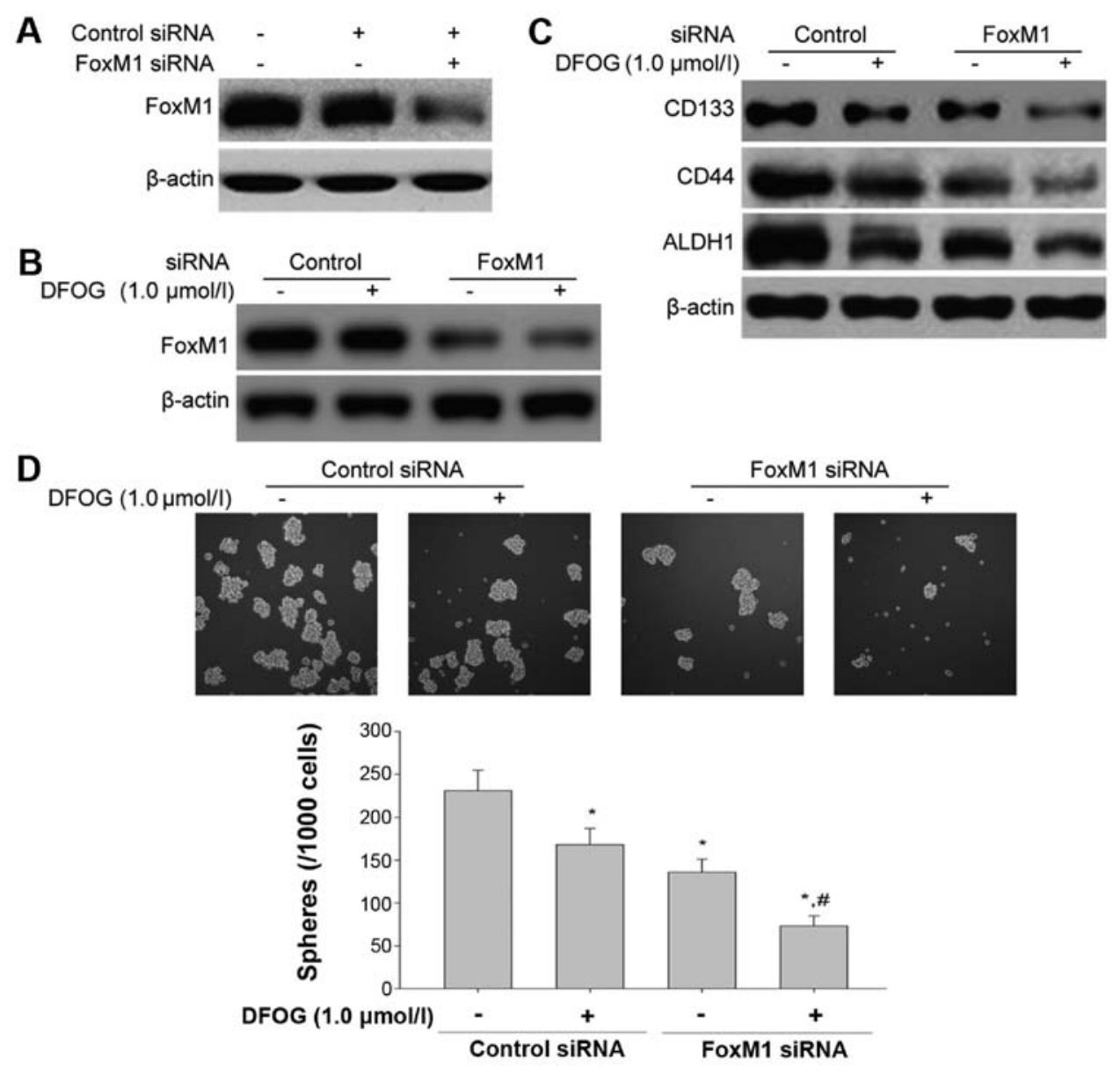

Figure 6. Synergistic effect on gastric cancer stem-like cells (GCSLCs) from SGC-7901 cells by DFOG and transfection of FoxM1 siRNA. (A) The protein expression of FoxM1 in sphere-forming cells (SFCs) was significantly decreased after transfection with FoxM1 siRNA. (B) Synergistic inhibition of expression of FoxM1 in SFCs by DFOG and FoxM1 siRNA transfection. (C) Synergistic inhibition of expression of CD133, CD44 and ALDH1 in SFCs by DFOG and FoxM1 siRNA transfection. (D) Synergistic inhibition of the sphere forming ability of SFCs by DFOG and FoxM1 siRNA transfection and the statistical analysis. ${ }^{*} \mathrm{P}<0.05$ vs. the group treated with $0.1 \%$ DMSO; ${ }^{*} \mathrm{P}<0.05$ vs. the group treated with $1.0 \mu \mathrm{mol} / 1 \mathrm{DFOG}$ alone.

the protein expression of a known mesenchymal phenotype cell biomarker (N-cadherin) and an epithelial phenotype cell biomarker (E-cadherin) by western blot analysis. The results demonstrated that the relative protein level of $\mathrm{N}$-cadherin was highly expressed in the GCSLCs, while that of E-cadherin was weakly expressed (Fig. 3C).
DFOG inhibits the self-renewal of GCSLCs derived from the $S G C-7901$ cell line. Tumor sphere assay is used to identify stem cells in in vitro assays. We examined the tumor sphere formation capacity of SGC-7901 cells following treatment of DFOG. The results showed that DFOG (1.0, 3.0 and $10.0 \mu \mathrm{mol} / \mathrm{l})$ reduced the number of SFCs derived from the 


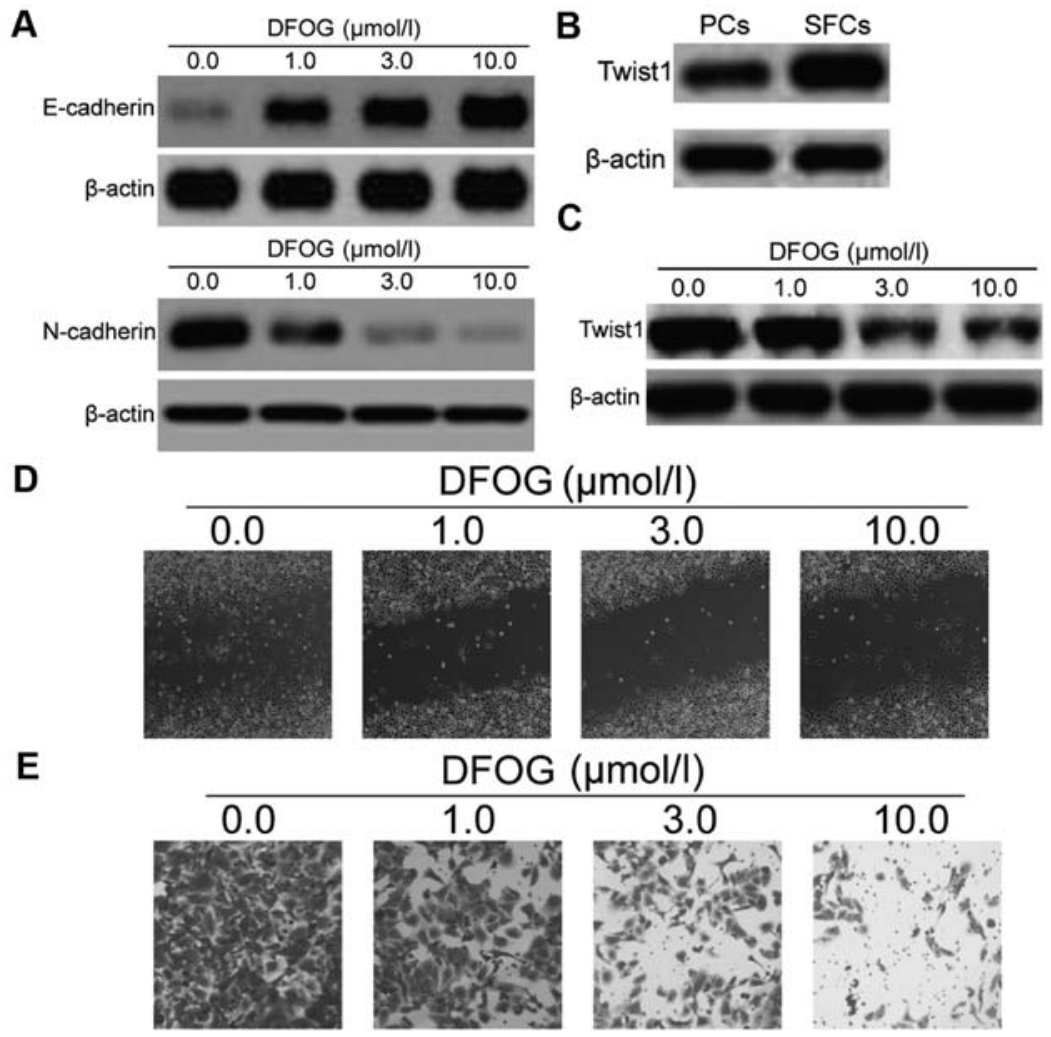

Figure 7. Effects of DFOG on EMT phenotype, migration and invasion capabilities in gastric cancer stem-like cells (GCSLCs) from SGC-7901 cells. (A) The increased expression of E-cadherin and decreased expression of N-cadherin in the sphere-forming cells (SFCs) following treatment with DFOG. (B) Western blot analysis showed that Twist1 was highly expressed in the SFCs. (C) The inhibition of the expression of Twist1 by DFOG in SFCs. (D) Inhibition of the migratory ability by DFOG in SFCs. (E) Inhibition of cell invasive ability by DFOG in SFCs.

SGC-7901 cells in a concentration-dependent manner (Fig. 4), indicating that DFOG is able to preferentially suppress the self-renewal of GCSLCs.

DFOG downregulates the expression of CSC markers and FoxM1 in GCSLCs derived from the SGC-7901 cell line. CD133, CD44 and ALDH1 are used as cancer stem cell markers in many types of tumor cells including GC. To investigate the effect of DFOG on GCSLC surface marker expression including CD44, CD133 and ALDH1, we incubated GCSLCs with DFOG (1.0, 3.0 and $10.0 \mu \mathrm{mol} / \mathrm{l})$ and DMSO as a control. The expression levels of CD44, CD133 and ALDH1 in the GCSLCs were significantly suppressed following treatment with DFOG compared with the spheres that were untreated (Fig. 5A). A previous study demonstrated that overexpression of FoxM1 led to EMT by the acquisition of the EMT phenotype and downregulation of FoxM1 led to the inhibition of EMT in GC cell lines (21). Therefore, the present study compared the level of FoxM1 protein expression in the PCs and SFCs and evaluated the inhibitory effect of DFOG on FoxM1. The results revealed that FoxM1 expression was higher in the SFCs in comparison with that in the PCs (Fig. 5B). Furthermore, as shown in Fig. 5C, the expression of FoxM1 in the SFCs was significantly reduced by DFOG in a dose-dependent manner.

Transfection of FoxM1 siRNA enhances the inhibitory effects of DFOG on the expression of FoxM1, CSC markers and the self-renewal in GCSLCs derived from the SGC-7901 cell line. We next transfected FoxM1 siRNA into the GCSLCs to confirm the inhibitory effect of DFOG on FoxM1 expression in GC cells and the effect of FoxM1 on the characteristics of GCSLCs. The GCSLCs were transfected with either scramble siRNA or FoxM1 siRNA. The expression levels of FoxM1 and CSC markers including CD133, CD44 and ALDH1 were assessed using western blot analysis. The results showed that the protein expression level of FoxM1 was inhibited following FoxM1 knockdown (Fig. 6A). Furthermore, after transfection of FoxM1 siRNA, the inhibitory effects of DFOG on the expression of FoxM1 and CSC markers (CD133, CD44 and ALDH1) were markedly enhanced compared with the scramble siRNA control group (Fig. 6B and C). The knockdown of FoxM1 also suppressed the sphere-forming capability of the GCSLCs and suppressed the inhibition of the self-renewal of GCSLCs synergistically together with DFOG (Fig. 6D).

DFOG reverses EMT, as well as decreases the migration and invasion of GCSLCs derived from the SGC-7901 cell line. To investigate the effects of DFOG on the EMT process of GCSLCs, the protein levels of E-cadherin, $\mathrm{N}$-cadherin and the Twistl (EMT-related transcription factors) were measured. The results from the western blot analysis demonstrated that DFOG upregulated the protein level of E-cadherin and downregulated the protein level of $\mathrm{N}$-cadherin (Fig. 7A). The protein expression level of Twist1 in the GCSLCs was higher than that in the PCs (Fig. 7B), while DFOG also dose-dependently suppressed the expression of Twistl (Fig. 7C). These results clearly demonstrated that DFOG could reverse EMT, relying 


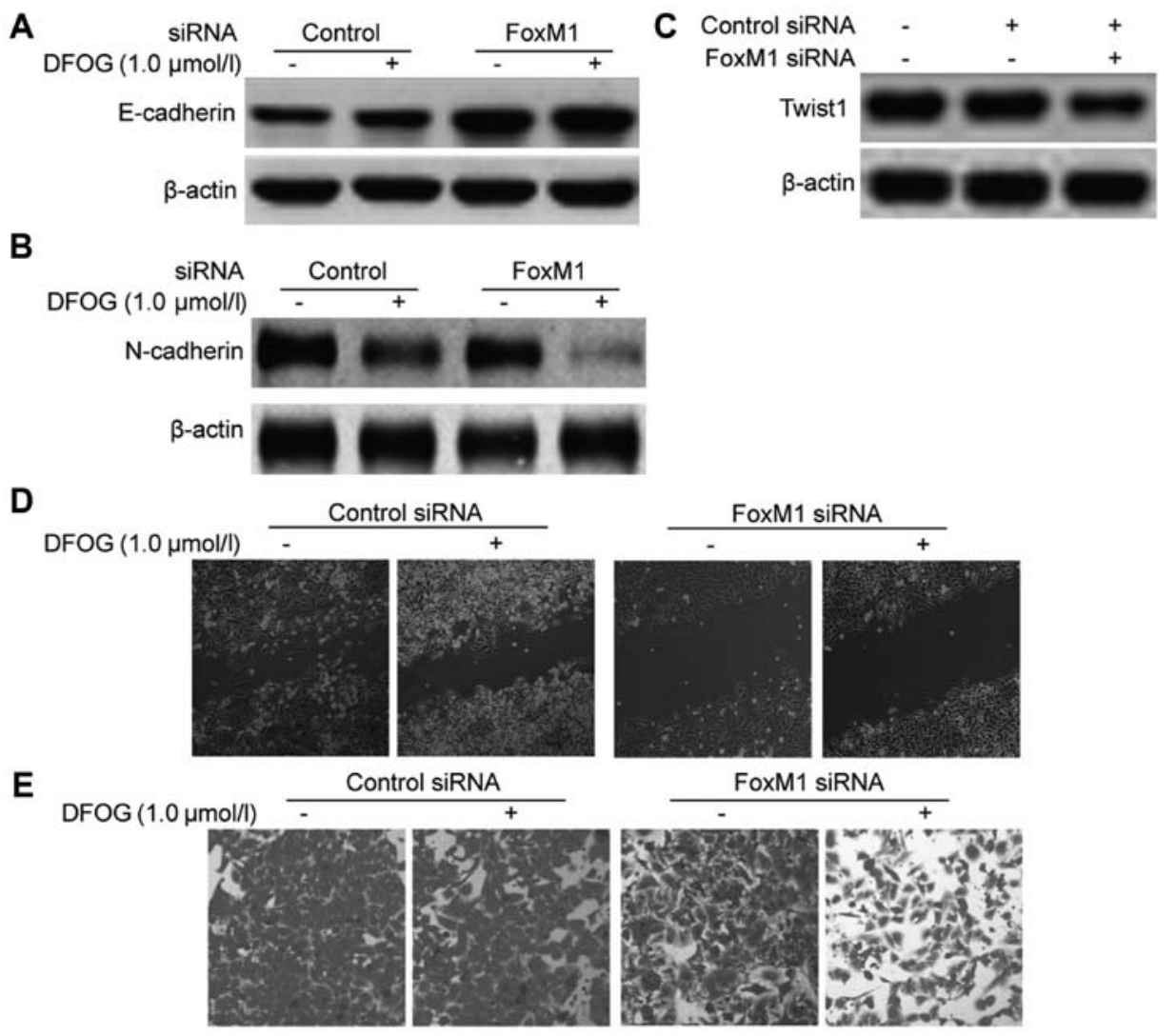

Figure 8. Transfection of FoxM1 siRNA cooperates with DFOG to reverse EMT. (A) The synergistic upregulation of E-cadherin in sphere-forming cells (SFCs) by DFOG and FoxM1 siRNA transfection. (B) Synergistic inhibition of N-cadherin in SFCs by DFOG and FoxM1 siRNA transfection. (C) Synergistic inhibition of Twist1 in SFCs by DFOG and FoxM1 siRNA transfection. (D) Synergistic inhibition of the migratory ability of SFCs by DFOG and FoxM1 siRNA transfection. (E) Synergistic inhibition of the migratory ability of SFCs by DFOG and FoxM1 siRNA transfection.

on inhibition of the EMT phenotypic biomarkers and Twist1. Migration and invasion abilities are important characteristics of CSCs responsible for tumor metastasis and growth. CSCs are assumed to have higher migration capacity than normal cancer cells and Twist1 is closely associated with cancer cell migration and invasion. Functionally, the relative migratory and invasive cell numbers of GCSLCs were significantly decreased when compared to these numbers in the negative control, suggesting that DFOG reduced cell migration and invasion in the GCSLCs (Fig. 7D and E). The above results showed that DFOG inhibited the expression of Twist1, leading to the inhibition of cancer cell migration and invasion.

Transfection of FoxMI siRNA cooperates with DFOG to reverse $E M T$. To examine whether forced knockdown of FoxM1 can cooperate with DFOG to reverse EMT, the protein expression of EMT biomarkers (E-cadherin and N-cadherin) and Twistl was measured by western blot analysis. As compared to the negative control groups, silencing by FoxM1 siRNA increased the protein expression of E-cadherin (Fig. 8A) and decreased the protein expression of $\mathrm{N}$-cadherin and Twist1 (Fig. 8B and C), suggested that knockdown of FoxM1 could reverse EMT. Moreover, transfection of FoxM1 siRNA also enhanced the upregulation of E-cadherin protein expression (Fig. 7A) and the downregulation of N-cadherin and Twist1 protein expression (Fig. $8 \mathrm{~B}$ and C) caused by DFOG, demonstrating that transfection of FoxM1 siRNA can cooperate with DFOG to reverse the EMT process. Following transfection of FoxM1 siRNA, the influence on the migratory and invasive capabilities of the GCSLCs were evaluated. The results showed that transfection of FoxM1 siRNA suppressed the migration and invasion of GCSLCs and also enhanced the inhibitory effect of DFOG on the migration and invasion of GCSLCs compared with the control group (Fig. 8D and E). These results confirmed that transfection of FoxM1 siRNA and DFOG can synergistically reverse the EMT process of GCSLCs.

\section{Discussion}

In the present study, it was confirmed that SFCs derived from the SGC-7901 cell line possessed superactive self-renewal capacity in vitro when compared with that noted in the parental cells. It was also found that $\mathrm{CD} 133^{+}, \mathrm{CD} 44^{+}$and ALDH-high populations were enriched in the tumor spheroid cells from the SGC-7901 cells, which exhibited the characteristics of GCSCs such as invasion capacity and EMT, and were therefore identified as GCSLCs.

Previous studies have confirmed that FoxM1 plays an important role in the regulation of cancer stem cell (CSC) properties and EMT in various types of cancers. Meng et al reported that overexpression of FoxM1 promotes EMT and metastasis of hepatocellular carcinoma (32). Miao et al reported that downregulation of FoxM1 leads to the inhibition 
of EMT in GC cells (21). Bao et al discovered that overexpression of FoxM1 led to EMT and a cancer stem cell phenotype in pancreatic cancer cells (22). In our previous study, we found that DFOG inhibited ovarian and GC cell growth by downregulation of FoxM1 (30). The present study uncovered, for the first time, that DFOG can inhibit the function and properties of GCSLCs through downregulation of FoxM1.

Twist1 is reported as one of the major inducers of the EMT process and also acts as an EMT biomarker in CSCs. Ren et al demonstrated that overexpression of Twist in HCC cell line SMMC-7721 promoted the generation of a hepatocellular cancer stem cell (HSC) phenotype through upregulation of the expression of the biomarkers CD133 and CD44 (33). $\mathrm{He}$ et al reported that casticin inhibited EMT in liver CSCs from the SMMC-7721 cell line by downregulating Twist (34). Our results showed that overexpression of Twist protein in GCSLCs were significantly suppressed by exposure to DFOG consistent with the increased expression of E-cadherin and decreased expression of $\mathrm{N}$-cadherin. These results revealed that the EMT process in GCSLCs was suppressed by DFOG. In addition, Qian et al reported that Twist1 promoted GC cell proliferation through upregulation of FoxM1, which suggested that Twist1 and FoxM1 can interact with each other to affect the function and properties of CSCs (35). Our current results indicated that DFOG was capable to reverse the EMT phenotype by downregulation of FoxM1 and further downregulation of Twist1 based on different mechanism when compared with that of FoxM1 siRNA.

Overall, our findings further clarify the anticancer effects of 7-difluoromethoxyl-5,4'-di-n-octyl genistein (DFOG), a novel synthetic genistein analogue. DFOG eliminated stemlike characteristics of GCSLCs and reversed EMT, partially due to the downregulation of FoxM1 and EMT-related proteins (Twist1), and attenuated the migratory and invasive abilities of GCSLCs. DFOG may be potentially effective in preventing GC by targeting CSCs.

\section{Acknowledgements}

The present study was financially supported by grants from the National Natural Science Foundation of China (nos. 31400311 and 81172375), the Program for Excellent Talents of Hunan Normal University (no. ET1508), the Project of Hunan Provincial Natural Science Foundation (no. 13JJ3061), the Scientific Research Fund of Hunan Normal University (nos. 140668 and 140666), and the Construct Program of the Key Discipline of Basic Medicine in Hunan Province.

\section{References}

1. Ferlay J, Shin HR, Bray F, Forman D, Mathers C and Parkin DM: Estimates of worldwide burden of cancer in 2008: GLOBOCAN 2008. Int J Cancer 127: 2893-2917, 2010.

2. Siegel R, Naishadham D and Jemal A: Cancer statistics, 2012. CA Cancer J Clin 62: 10-29, 2012.

3. Bonnet D and Dick JE: Human acute myeloid leukemia is organized as a hierarchy that originates from a primitive hematopoietic cell. Nat Med 3: 730-737, 1997.

4. Ignatova TN, Kukekov VG, Laywell ED, Suslov ON, Vrionis FD and Steindler DA: Human cortical glial tumors contain neural stem-like cells expressing astroglial and neuronal markers in vitro. Glia 39: 193-206, 2002.
5. Al-Hajj M, Wicha MS, Benito-Hernandez A, Morrison SJ and Clarke MF: Prospective identification of tumorigenic breast cancer cells. Proc Natl Acad Sci USA 100: 3983-3988, 2003.

6. Yu SC, Ping YF, Yi L, Zhou ZH, Chen JH, Yao XH, Gao L, Wang JM and Bian XW: Isolation and characterization of cancer stem cells from a human glioblastoma cell line U87. Cancer Lett 265: 124-134, 2008.

7. Kim Y, Wu Q, Hamerlik P, Hitomi M, Sloan AE, Barnett GH, Weil RJ, Leahy P, Hjelmeland AB and Rich JN: Aptamer identification of brain tumor-initiating cells. Cancer Res 73: 4923-4936, 2013.

8. Li C, Heidt DG, Dalerba P, Burant CF, Zhang L, Adsay V, Wicha M, Clarke MF and Simeone DM: Identification of pancreatic cancer stem cells. Cancer Res 67: 1030-1037, 2007.

9. Chen K, Huang YH and Chen JL: Understanding and targeting cancer stem cells: Therapeutic implications and challenges. Acta Pharmacol Sin 34: 732-740, 2013.

10. Takaishi S, Okumura T, Tu S, Wang SS, Shibata W, Vigneshwaran R, Gordon SA, Shimada Y and Wang TC: Identification of gastric cancer stem cells using the cell surface marker CD44. Stem Cells 27: 1006-1020, 2009.

11. Jiang J, Zhang Y, Chuai S, Wang Z, Zheng D, Xu F, Zhang Y, Li C, Liang Y and Chen Z: Trastuzumab Herceptin) targets gastric cancer stem cells characterized by CD90 phenotype. Oncogene 31: 671-682, 2012.

12. Han M, Liu M, Wang Y, Chen X, Xu J, Sun Y, Zhao L, Qu H, Fan Y and Wu C: Antagonism of miR-21 reverses epithelialmesenchymal transition and cancer stem cell phenotype through AKT/ERK1/2 inactivation by targeting PTEN. PLoS One 7: e39520, 2012.

13. Li K, Dan Z and Nie YQ: Gastric cancer stem cells in gastric carcinogenesis, progression, prevention and treatment. World $\mathrm{J}$ Gastroenterol 20: 5420-5426, 2014.

14. Liu J, Ma L, Xu J, Liu C, Zhang J, Liu J, Chen R and Zhou Y: Spheroid body-forming cells in the human gastric cancer cell line MKN-45 possess cancer stem cell properties. Int J Oncol 42: 453-459, 2013.

15. Kim IM, Ackerson T, Ramakrishna S, Tretiakova M, Wang IC, Kalin TV, Major ML, Gusarova GA, Yoder HM, Costa RH, et al: The Forkhead Box m1 transcription factor stimulates the proliferation of tumor cells during development of lung cancer. Cancer Res 66: 2153-2161, 2006.

16. Zeng J, Wang L, Li Q, Li W, Björkholm M, Jia J and Xu D: FoxM1 is up-regulated in gastric cancer and its inhibition leads to cellular senescence, partially dependent on $p 27^{k i p 1}$. J Pathol 218: 419-427, 2009.

17. Wang Z, Banerjee S, Kong D, Li Y and Sarkar FH: Downregulation of Forkhead Box M1 transcription factor leads to the inhibition of invasion and angiogenesis of pancreatic cancer cells. Cancer Res 67: 8293-8300, 2007.

18. Laoukili J, Stahl M and Medema RH: FoxM1: At the crossroads of ageing and cancer. Biochim Biophys Acta 1775: 92-102, 2007.

19. Wang IC, Ustiyan V, Zhang Y, Cai Y, Kalin TV and Kalinichenko VV: Foxm1 transcription factor is required for the initiation of lung tumorigenesis by oncogenic Kras ${ }^{\mathrm{G} 12 \mathrm{D}}$. Oncogene 33: 5391-5396, 2014.

20. Yu G, Zhou A, Xue J, Huang C, Zhang X, Kang SH, Chiu WT, Tan C, Xie K, Wang J, et al: FoxM1 promotes breast tumorigenesis by activating PDGF-A and forming a positive feedback loop with the PDGF/AKT signaling pathway. Oncotarget 6: 11281-11294, 2015.

21. Miao L, Xiong X, Lin Y, Cheng Y, Lu J, Zhang J and Cheng N: Down-regulation of FoxM1 leads to the inhibition of the epithelial-mesenchymal transition in gastric cancer cells. Cancer Genet 207: 75-82, 2014.

22. Bao B, Wang Z, Ali S, Kong D, Banerjee S, Ahmad A, Li Y, Azmi AS, Miele L and Sarkar FH: Over-expression of FoxM1 leads to epithelial-mesenchymal transition and cancer stem cell phenotype in pancreatic cancer cells. J Cell Biochem 112: 2296-2306, 2011.

23. Ning YX, Li QX, Ren KQ, Quan MF and Cao JG: 7-Difluoromethoxyl-5,4'-di-n-octyl genistein inhibits ovarian cancer stem cell characteristics through the downregulation of FOXM1. Oncol Lett 8: 295-300, 2014.

24. Yang J, Mani SA, Donaher JL, Ramaswamy S, Itzykson RA, Come C, Savagner P, Gitelman I, Richardson A and Weinberg RA: Twist, a master regulator of morphogenesis, plays an essential role in tumor metastasis. Cell 117: 927-939, 2004.

25. Khan MA, Chen HC, Zhang D and Fu J: Twist: A molecular target in cancer therapeutics. Tumour Biol 34: 2497-2506, 2013. 
26. Bourgeois P, Stoetzel C, Bolcato-Bellemin AL, Mattei MG and Perrin-Schmitt F: The human H-twist gene is located at 7p21 and encodes a B-HLH protein that is $96 \%$ similar to its murine M-twist counterpart. Mamm Genome 7: 915-917, 1996.

27. Vesuna F, Lisok A, Kimble B and Raman V: Twist modulates breast cancer stem cells by transcriptional regulation of CD24 expression. Neoplasia 11: 1318-1328, 2009.

28. Li J and Zhou BP: Activation of $\beta$-catenin and Akt pathways by Twist are critical for the maintenance of EMT associated cancer stem cell-like characters. BMC Cancer 11: 49, 2011.

29. Xiang HL, Liu F, Quan MF, Cao JG and Lv Y: 7-difluoromethoxyl-5,4'-di-n-octylgenistein inhibits growth of gastric cancer cells through downregulating forkhead box M1. World J Gastroenterol 18: 4618-4626, 2012.

30. Ning Y, Luo C, Ren K, Quan M and Cao J: FOXO3a-mediated suppression of the self-renewal capacity of sphere-forming cells derived from the ovarian cancer SKOV3 cell line by 7-difluoromethoxyl-5,4'-di-n-octyl genistein. Mol Med Rep 9: 1982-1988, 2014.
31. Cao JG, Cao XZ and Xiang HL: Patent CN 201210591131.2. Filed December 22, 2012.

32. Meng FD, Wei JC, Qu K, Wang ZX, Wu QF, Tai MH, Liu HC, Zhang RY and Liu C: FoxM1 overexpression promotes epithelial-mesenchymal transition and metastasis of hepatocellular carcinoma. World J Gastroenterol 21: 196-213,2015.

33. Ren KQ, Cao XZ, Liu ZH, Guo H, Quan MF, Liu F, Jiang L, Xiang HL, Deng XY and Cao JG: 8-Bromo-5-hydroxy-7methoxychrysin targeting for inhibition of the properties of liver cancer stem cells by modulation of Twist signaling. Int J Oncol 43: 1719-1729, 2013.

34. He M, Cao XC, He GC, Sheng XF, Ai XH and Wu YH: Casticin inhibits epithelial-mesenchymal transition of liver cancer stem cells of the SMMC-7721 cell line through downregulating Twist. Oncol Lett 7: 1625-1631, 2014.

35. Qian J, Luo Y, Gu X, Zhan W and Wang X: Twist1 promotes gastric cancer cell proliferation through up-regulation of FoxM1. PLoS One 8: e77625, 2013. 